\title{
A comparative perspective on minicolumns and inhibitory GABAergic interneurons in the neocortex
}

\author{
1 Department of Anthropology and School of Biomedical Sciences, Kent State University, Kent, OH, USA \\ 2 Department of Anthropology, The George Washington University, Washington, DC, USA \\ 3 Department of Neuroscience, Mount Sinai School of Medicine, New York, NY, USA \\ ${ }^{4}$ New York Consortium in Evolutionary Primatology, New York, NY, USA
}

Mary Ann Raghanti ${ }^{*}$, Muhammad A. Spocter ${ }^{2}$, Camilla Butti ${ }^{3}$, Patrick R. Hof ${ }^{3,4}$ and Chet C. Sherwood ${ }^{2}$

\section{Edited by:}

Javier DeFelipe, Cajal Institute, Spain

\section{Reviewed by:}

Manuel Casanova, University of Louisville, USA

Javier DeFelipe, Cajal Institute, Spain

\section{${ }^{*}$ Correspondence:}

Mary Ann Raghanti, Department of

Anthropology, 226 Lowry Hall, Kent

State University, Kent, $\mathrm{OH} 44242$,

USA.

e-mail:mraghant@kent.edu
Neocortical columns are functional and morphological units whose architecture may have been under selective evolutionary pressure in different mammalian lineages in response to encephalization and specializations of cognitive abilities. Inhibitory interneurons make a substantial contribution to the morphology and distribution of minicolumns within the cortex. In this context, we review differences in minicolumns and GABAergic interneurons among species and discuss possible implications for signaling among and within minicolumns. Furthermore, we discuss how abnormalities of both minicolumn disposition and inhibitory interneurons might be associated with neuropathological processes, such as Alzheimer's disease, autism, and schizophrenia. Specifically, we explore the possibility that phylogenetic variability in calcium-binding protein-expressing interneuron subtypes is directly related to differences in minicolumn morphology among species and might contribute to neuropathological susceptibility in humans.

Keywords: calcium-binding proteins, calbindin, calretinin, parvalbumin, neuropathology, evolution

\section{INTRODUCTION}

Vernon Mountcastle was the first to describe the cortical minicolumn (Mountcastle et al., 1955), providing what appeared to be a simple means by which to understand the cerebral cortex. According to this model of cortical organization, neurons, glia, and their connections form part of an all-encompassing vertical system which unites the cells of each minicolumn into a coordinated functional unit (Mountcastle, 1997). In this context, the smallest unit of cortical anatomy is the minicolumn, which is defined by a narrow radial array of single neurons. Minicolumns are arranged within larger macrocolumns (e.g., barrel somatosensory cortex of the rodent).

While the minicolumn has arguably brought a coherent sense of structure to our thinking, the pursuit of simple explanations has been fueled by an ancillary argument for regularity in cortical minicolumn morphometry. Influential in this regard has been the highly cited paper by Rockel et al. (1980) that reinforced the claim that there is a fundamentally uniform architecture to the cortical minicolumn, reporting that the number of neurons within a minicolumn (defined as the number of neurons within a strip of tissue $30-\mu \mathrm{m}$ wide and $25-\mu \mathrm{m}$ thick from pial surface to white matter) is nearly invariant at 110 neurons across cytoarchitectonic areas and species, suggesting that functional differences were principally a result of wiring (Rockel et al., 1980). The claim that cortical minicolumns are uniform reified the philosophical idea that human and animal differences can be reduced to purely quantitative measures (Rakic, 2008) and added validity to the widespread use of macaque and mouse models in neurobiology. In addition, it seemed, at least in principle, to be congruent with the existence of the ontogenetic columns described in Pasko Rakic's "radial unit hypothesis", which provided a basis for understanding how evolutionary changes in the neocortex occur through modifications of cell cycle dynamics of founder neurons in the ventricular zone during development.

Subsequent work demonstrated that the estimates of neuron numbers for the cortical minicolumn as described by Rockel et al. (1980) were flawed for various reasons, including problems with extrapolating from counts in different cytoarchitectonic areas without corrections for cell size and arbitrary designations for the expected dimensions of a cortical minicolumn (DeFelipe et al., 2002; Rakic, 2008). Further empirical evidence has also shown that there is much greater phylogenetic variation in the number of neurons underneath $1 \mathrm{~mm}^{2}$ of cortex than was previously thought (e.g., Herculano-Houzel et al., 2008). Although several investigators have directly refuted the validity of the Rockel et al. (1980) claim (e.g., Preuss and Goldman-Rakic, 1991; Beaulieu, 1993; Skoglund et al., 1996; DeFelipe et al., 2002; Casanova et al., 2009), the concept of uniformity in cortical minicolumn structure still remains popular and is widely used in computational models of cortical operation.

Recent research on the histological organization of the neocortex across mammals, however, has demonstrated a rich diversity of structural variants, ranging from the morphology of astrocytes to the packing density of neurons. In this review, we will examine species diversity in two key elements of neocortical structure-interneurons and minicolumns. Variability in minicolumn structure will be linked to known phylogenetic differences in calbindin- $(\mathrm{CB})$, calretinin(CR), and parvalbumin (PV)-immunoreactive (ir) interneuron populations with the aim of assessing the possible implications of variation in minicolumn subcomponents on the evolution of inter/ intracolumnar communication. Furthermore, we will discuss how 
an appreciation for minicolumn and interneuron variability may shed light on neuropathologies associated with cognitive deficits. We propose that the appearance of a specific GABAergic interneuron subtype within the Primate Order, the double bouquet cell, has made a significant contribution to unique minicolumn functions and human susceptibility to specific neuropathologies.

\section{COMPARATIVE ASSESSMENT OF MINICOLUMNS: DIVERSITY AMONG MAMMALS}

A major obstacle in dispelling the assertion that there is uniformity in minicolumn size is the lack of systematic, standardized data on minicolumn dimensions across a wide range of species (Buxhoeveden and Casanova, 2002a). The data that are currently available represent different methodological and measurement techniques from tissues that were prepared in a manner that might be susceptible to differential shrinkage of histological components. Further, cortical minicolumns have not been examined in a very wide range of brain sizes, so we currently do not know if there are upper and lower bounds for cortical minicolumn dimensions or if there are regular patterns related to the extent of gyrification (Buxhoeveden and Casanova, 2002a). Although current comparative data on minicolumn width are not ideal, they do permit a tentative examination of variability within a limited range of species. As reported from the literature, minicolumn width appears to vary substantially among species and across cortical areas (Figure 1).

If we limit ourselves to considering only minicolumn widths reported for the visual cortex using the apical dendrite bundle as the defining feature, it is apparent that the primary visual cortex of the rhesus macaque (Macaca mulatta) has, on average, a smaller minicolumn width $(23-30 \mu \mathrm{m})$ compared to that reported for

Pyramidal cell array

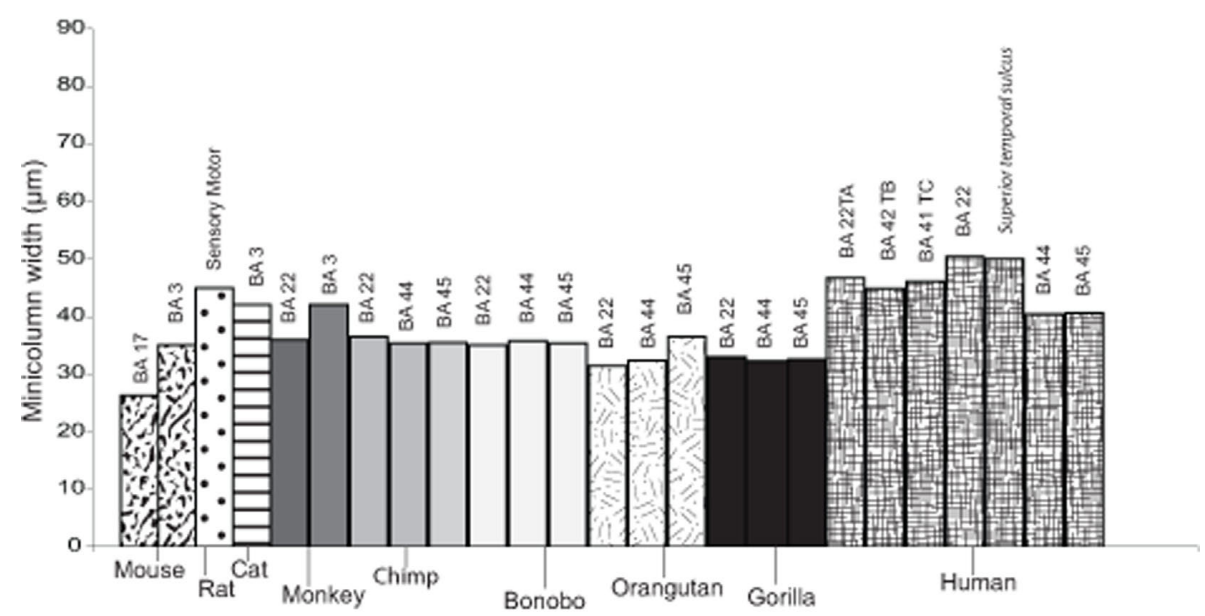

Apical dendrite bundle

Other methods
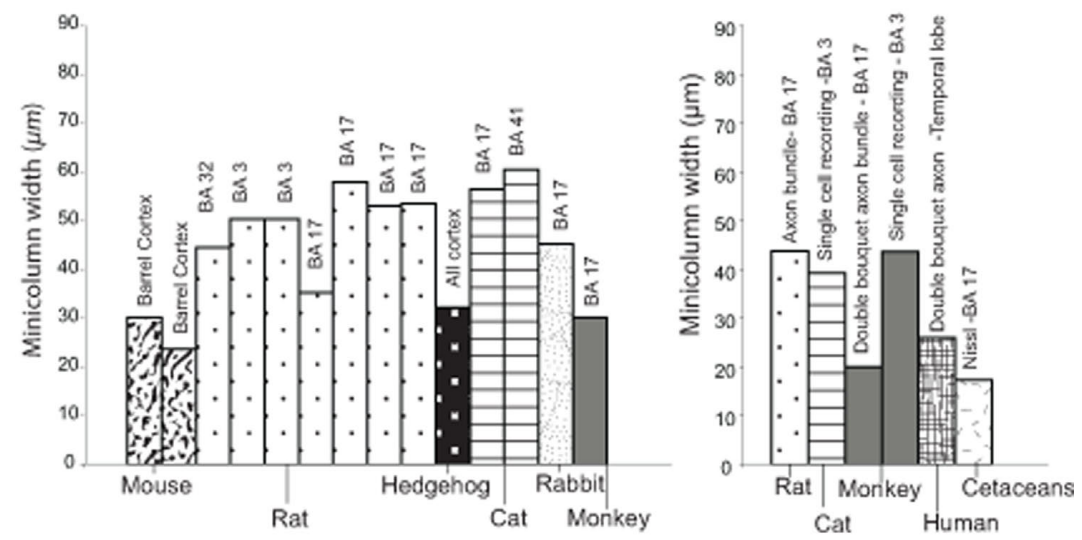

FIGURE 1 | Minicolumn widths collated from the literature for the Class Mammalia. The following sources were used: Escobar et al. (1986), White and Peters (1993), Peters and Yilmaz (1993), Feldman and Peters (1974), Favorov and Diamond (1990), Tommerdahl et al. (1993), Gabbott and Bacon (1996), Peters and Walsh (1972), Peters and Kara (1987), Kohn et al. (1997), Fleischauer et al. (1972), DeFelipe et al. (1990), Peters and Sethares (1991), Peters and Sethares
(1996), Peters and Sethares (1997), Buxhoeveden et al. (2001a), Von Bonin and Mehler (1971), Kaas et al. (1981), Buxhoeveden et al. (2002a), Schlaug et al. (1995), Seldon (1981), del Rio and DeFelipe (1997a), Buldyrev et al. (2000); and Casanova and Tilquist (2008). Note that in certain cases an average minicolumn width had been computed by calculating the mean based on the minimum and maximum values reported in each study. Numbers refer to Brodmann areas. 
rats $(30-40 \mu \mathrm{m}$, average $35 \mu \mathrm{m})$, cats $(55-60 \mu \mathrm{m}$, average $57.5 \mu \mathrm{m})$ and rabbits $(40-50 \mu \mathrm{m}$, average $45 \mu \mathrm{m})$. Interestingly, even though the brain of the rhesus macaque is approximately 4-fold larger in size than that of a cat (macaque: $106.4 \mathrm{cc}$; cat: $25.3 \mathrm{cc}$ ), there is not a concomitant increase in minicolumn width (Peters and Yilmaz, 1993). Peters and Yilmaz (1993) speculated that this may be the case because macaques might possess more complex cell columns, which render a more detailed specification of information, thereby permitting a reduction in overall minicolumn width. A more recent analysis of the morphometric variability of minicolumns among macaque monkeys, humans, and chimpanzees (Casanova et al., 2009) again confirmed that there are differences in minicolumn width across species, but concluded that the core column space (i.e., the space that contains the majority of neurons and fibers and is distinguishable from the adjacent, cell-poor neuropil space) remains relatively invariant, suggesting that this subcomponent of the cortical minicolumn may be evolutionary conserved (Casanova et al., 2009). It is possible that conservation of the minicolumn core dimension in these three species may be confined to this particular clade, and only further comparisons to other species will elucidate whether this apparent uniformity is indicative of an upper or lower bound for all primates or mammals as a whole. The above examples, although tentative, highlight the need for casting the comparative next even wider to include other as yet unexamined species and emphasize how an analysis sensitive to diversity in minicolumn attributes may provide an interpretation which is more functionally and ecologically linked to the environments within which species evolved.

For example, it is notable that a similar "primate-like" pattern of smaller minicolumn sizes $(19.9 \mu \mathrm{m})$ were reported for the visual cortex of large brained Cetacea (humpback whale, Megaptera novaeangliae, striped dolphin, Stenella coeruleoalba and bottlenose dolphin, Tursiops truncatus), who also have cortical minicolumns that are more discontinuous across cortical areas (Morgane et al., 1988; Manger, 2006; Hof and Van der Gucht, 2007). This specific feature of cortical organization in cetaceans is likely countered by integration of column activity occurring in their thick layer I which contains approximately $70 \%$ of the total cortical synapses (Glezer and Morgane, 1990). Strikingly, the cytoarchitectonic columns in the visual cortex of the striped dolphin and human contain roughly the same amount of synapses, indicating that any deficit or equivalence in cell column width is not necessarily indicative of the functional output of the cortical column for that species (Morgane et al., 1988), a point most strongly highlighted by the complex behavioral and cognitive abilities of cetaceans that compares with those of anthropoid primates (Marino, 2002; Marino et al., 2007, 2008).

Such species differences in minicolumn width for the visual cortex argue strongly in favor of further investigation into speciesspecific adaptations, especially as similar patterns may be expected for other regions of the cerebral cortex. Investigations of homologous areas of the primate cortex have indeed reported speciesspecific differences in minicolumn size and morphology. An example of this was reported in Wernicke's area homologue (area Tpt or area 22) of humans, macaque monkeys, and chimpanzees (Buxhoeveden and Casanova, 2000). Minicolumns in the left hemisphere of the human were $30 \%$ wider than those of the chimpanzee and macaque, with more neuropil space and less dense core areas (Buxhoeveden and Casanova, 2000; Buxhoeveden et al., 2001a). As indicated in Figure 1, minicolumn width measured in area 22 appears relatively uniform in macaque monkeys ( $36 \mu \mathrm{m})$, chimpanzees $(35-36.5 \mu \mathrm{m})$, gorillas $(33 \mu \mathrm{m})$, and orangutans $(31.4 \mu \mathrm{m})$, but humans possess larger minicolumn sizes $(50.4 \mu \mathrm{m})$. This difference would seemingly agree with restructuring in the human auditory cortex (Rilling et al., 2008) supposed to underlie human unique language abilities. In further support of this hypothesis, humans also display significantly larger minicolumn spacing in Broca's area (areas 44 and 45) than that observed for great apes (chimpanzee, bonobo, gorilla and orangutan) (Schenker et al., 2008).

A further argument in favor of recognizing the functional significance of diversity in the cortical minicolumn may be gleaned from studies of minicolumn widths among individuals of the same species and how these may relate to normal variation within a population. Casanova et al. (2007) recently reported significant differences in minicolumn width and mean cell spacing of a control group compared to that of three distinguished scientists. This study highlights the possibility for genetic and environmental effects on minicolumn phenotype, such as the number of founder cells, the duration of cell division cycle and selective cell death (see Rakic and Kornack, 2001). Minicolumn widths across a sample of the normal population shows continuous variation, suggesting that multiple independent variables may characterize its morphometry (Casanova, 2006). This is likely a reflection that, like other parts of the human organism, the cortical column may be (at least in part) prone to the effects of natural selection and adaptation.

Aside from size, minicolumns in different species may also show variability in their structural subcomponents (i.e., fibers and neurons). The following section is aimed at reviewing the evidence for phylogenetic differences indicative of diversity in the microcircuitry of mammalian cortical structure, with a focus on different subtypes of $\gamma$-aminobutyric acid (GABA)-containing interneurons.

\section{GABAergic INTERNEURONS AND CORTICAL MINICOLUMNS}

Inhibitory GABAergic interneurons are a heterogeneous group of cells that govern local cortical microcircuitry and are fundamental for intra- and intercolumnar processing (Hendry, 1987; DeFelipe, 2002; Casanova et al., 2003; Buzsaki et al., 2004; Ascoli et al., 2008). Whereas the morphological subtypes of interneurons that participate in cortical microcircuit regulation are highly conserved among mammals (Sherwood et al., 2009), there is a significant amount of variation among phyla in their diversity, density, distribution, and developmental patterns (e.g., Hof et al., 1999; Preuss and Coleman, 2002; Hof and Sherwood, 2005; Sherwood et al., 2007). For example, in rodents and other non-primate species, inhibitory interneurons comprise $15 \%$ or less of the cortical neuron population, whereas they may constitute more than $20 \%$ within the primate cortex (Hendry et al., 1987; Beaulieu et al., 1992; Gabbott and Bacon, 1996; Gabbott et al., 1997; DeFelipe et al., 1999, 2002). Additionally, the embryonic origin and migration of GABAergic cells has been demonstrated to differ between rodents and primates, with additional sites of neurogenesis in the lateral ventricular neurepithelium in primates (Petanjek et al., 2009). The different origins of GABAergic interneuron subpopulations undoubtedly relate to species-specific distributions within the neocortex and likely 
support differences in cognitive abilities. Inhibitory interneurons can be classified into subpopulations based on their immunoreactivity for the three calcium-binding proteins, $\mathrm{CB}, \mathrm{CR}$, and PV. Greater than $90 \%$ of all cortical GABAergic interneurons colocalize with one of these markers with little overlap among the separate populations (Hendry et al., 1989; Glezer et al., 1993; DeFelipe, 1997; Zaitsev et al., 2005). Different classes of interneurons interact with pyramidal cells to modulate cortical circuit processing, with CBand CR-ir neurons involved mostly in intracolumnar communication and PV-ir interneurons involved in transcolumnar signaling Figure 2 illustrates the major GABAergic cell types and Figures 3 and 4 show examples of $\mathrm{CB}, \mathrm{CR}$, and PV immunostaining.

Cortical PV-ir GABAergic neurons are predominantly multipolar and include large basket and chandelier cells (Condé et al., 1994; Gabbott et al., 1997; Zaitsev et al., 2005; see Figure 2). The large basket cells have long-range axons that extend horizontally, targeting the perikaryon of pyramidal cells of different minicolumns (Lund and Lewis, 1993; DeFelipe, 1997; Somogyi et al., 1998).
Chandelier cells, which are immunoreactive for PV, also provide lateral inhibition, making synaptic connections with the axon initial segments of pyramidal cells (DeFelipe, 1997; Wang et al., 2000a,b; Li et al., 2002). These various morphological classes of PV-ir cells regulate the rhythmic oscillations of pyramidal cell populations and have been identified as fast-spiking based on their brief action potentials and the absence of spike adaptation (Zaitsev et al., 2005; Sohal et al., 2009).

Cortical CR-ir interneurons have variable morphology and include bipolar, double bouquet, and Cajal-Retzius cells (DeFelipe, 1997). Bipolar and double bouquet CR-ir cells have axonal arbors that extend vertically, mostly targeting the dendrites of pyramidal cells in different layers of the cortex within a narrow column (DeFelipe et al., 1989; DeFelipe, 1997; del Rio and DeFelipe, 1997b; see Figure 2).

The characteristic phenotype of CB-ir interneurons in primate cortex is the double bouquet cell. As with the CR-ir double bouquet cells, CB-ir double bouquet axons provide vertical inhibition to pyramidal cells within the minicolumn (DeFelipe et al., 1989,

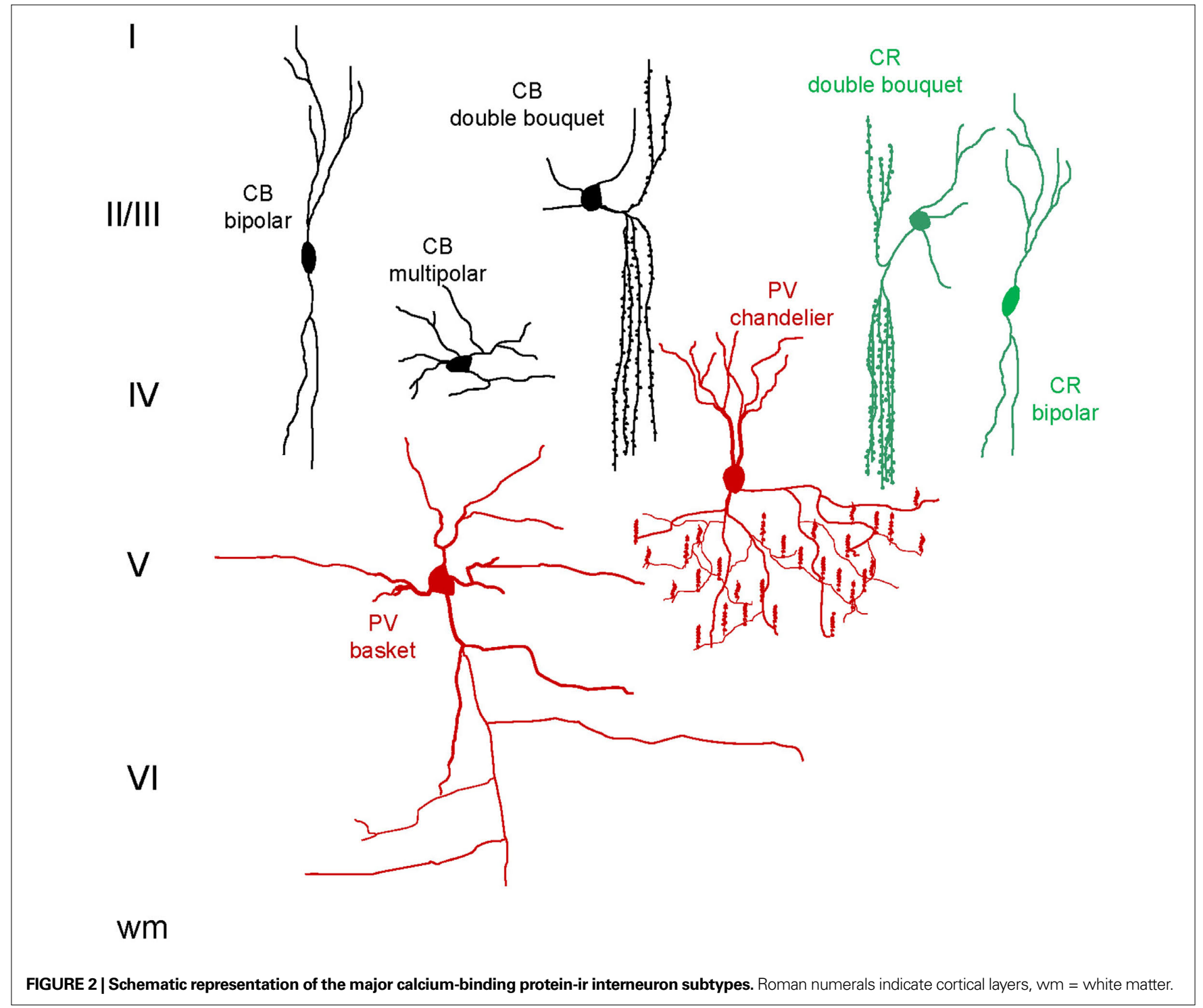



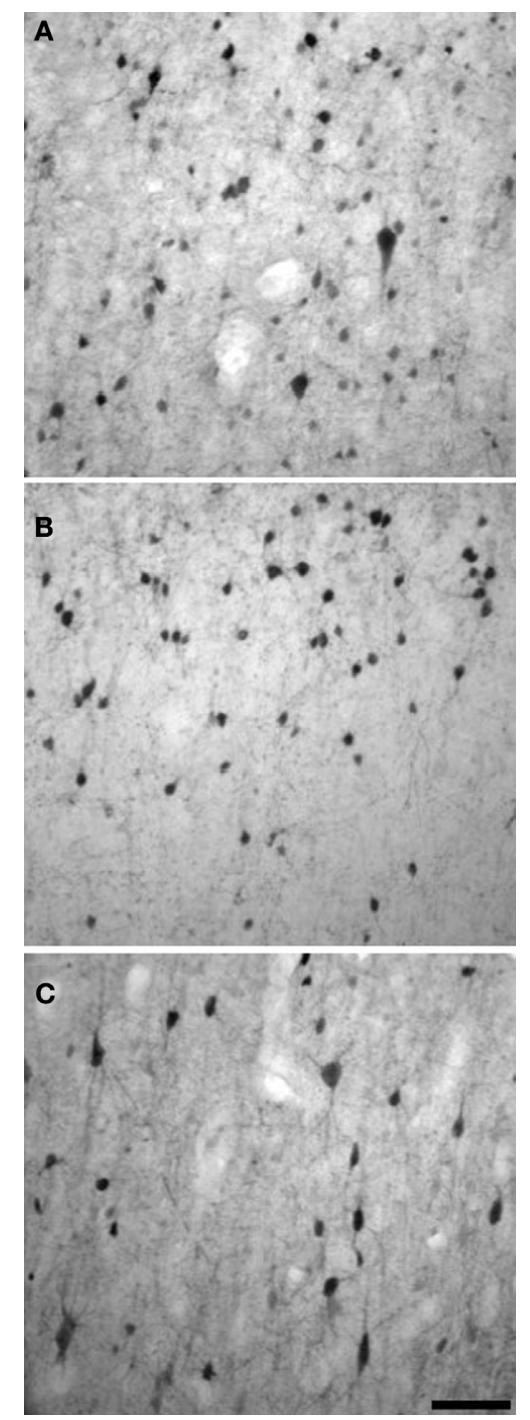

FIGURE 3 | Examples of CB (A), CR (B), and PV (C) immunostaining in layers II/III of chimpanzee motor cortex. Scale bar $=50 \mu \mathrm{m}$.
2006; Ballesteros-Yañez et al., 2005). In most non-primates except carnivores, CB-ir interneurons are mainly multipolar and bitufted, but lacking in the double bouquet morphotype (Ballesteros-Yañez et al., 2005; see Figure 2). Both CR- and CB-ir interneurons exhibit characteristics of non-fast-spiking cells in nonhuman primate cortex, with longer spike frequency and spike adaptation, but without distinctive differences between the two subpopulations (Zaitsev et al., 2005). Although CR- and CB-ir interneurons share similar physiological properties, the work of Zaitsev and colleagues suggests different pre- and postsynaptic connections, with CB-ir interneuron axons extending through cortical layers and accessing the cells of layer I, while CR-ir interneuron axons stop short of this layer.

GABAergic interneurons, particularly CB-ir double bouquet cells, contribute significantly to the morphology and distribution of minicolumns within the primate cortex (Buxhoeveden and Casanova, 2002b; Casanova et al., 2009). As a potential source for minicolumn diversity, we outline below the range of variation known for GABAergic neurons in mammals.

\section{GABAergic NEURON VARIABILITY AMONG MAMMALS}

The distributions of the calcium-binding protein-expressing interneurons have been reported for a variety of mammals, with a significant amount of diversity among species (Glezer et al., 1992, 1993, 1998; Hof et al., 1996, 1999; Hof and Sherwood, 2005; Zaitsev et al., 2005; Sherwood et al., 2007, 2009). Differences in GABAergic cell phenotype and density among species would be expected to represent alterations in local microcircuit processing, possibly supporting the expansion and differentiation of the cerebral cortex throughout mammalian evolution. Here we will highlight some of the major differences among mammals in terms of GABAergic cell populations (for review see Hof et al., 1999; Hof and Sherwood, 2005; Sherwood et al., 2009).

In primates, the three calcium-binding proteins are expressed in largely non-overlapping subpopulations of cortical interneurons (Gabbott and Bacon, 1996; DeFelipe et al., 1999; Zaitsev et al., 2005). In contrast, rodents show a greater degree of overlap, with colocalization of more than one calcium-binding protein expressed in the same cell (Kubota et al., 1994; Kawaguchi and Kubota, 1997). This difference in subpopulations in primates may support an enhanced,
A

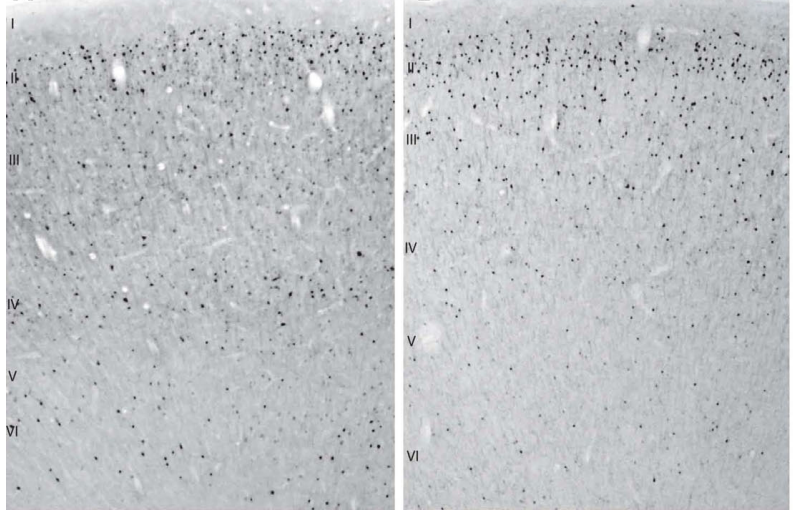

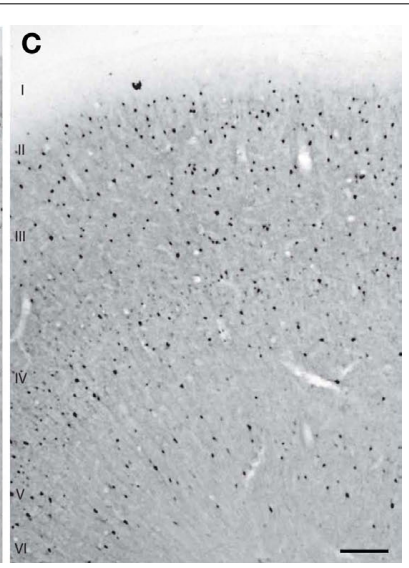

FIGURE 4 | Examples of CB (A), CR (B), and PV (C) immunostaining from layer I through layer VI in baboon parietal cortex. Scale bar = 500 um. 
or specialized, capability for specificity in local inhibitory control. In addition, the proportion of cortical interneurons varies among species, with primates having a higher overall percentage relative to rodents, afrotherians, and xenarthrans; though it is noteworthy that cetaceans have more than any of the terrestrial mammals that have been examined (Hof et al., 2000; DeFelipe et al., 2002; Sherwood et al., 2009).

In addition to variation in the relative concentration of cortical GABAergic cells, electrophysiological response properties can vary as well. A recent comparison of PV-ir fast-spiking basket cells in macaque monkeys and rats reported no significant morphological differences between species (Povysheva et al., 2008). However, Povysheva and colleagues did find a significant difference in excitability of PV-ir basket cell physiology, with neurons of macaque monkeys having a higher input resistance and lower firing threshold than those of rats. This finding coincides with differential firing of prefrontal cortex neurons during working memory task time delays, with lower frequency firing rates reported for rats (Povysheva et al., 2008). The actions of PV-ir interneurons appear to be fundamental for success in working memory tasks (Rao et al., 1999) and other cognitive functions (Constantinidis et al., 2002).

Phenotypic and morphological variation within interneuron subpopulations among species has also been reported. For example, chandelier cells express PV in primate primary motor and somatosensory cortex (DeFelipe et al., 1990), but not in canids (Hof et al., 1996). Further, CB-ir double bouquet cells are absent in rodents, lagomorphs, artiodactyls (Ballesteros-Yañez et al., 2005), xenarthrans, and afrotherians (Sherwood et al., 2009), but are present in the cortex of humans, macaque monkeys, and to a lesser extent and mostly restricted to visual cortex, in carnivores (BallesterosYañez et al., 2005). These cells are found within layers II and III and are characterized by long descending bundles of axon collaterals that are columnar in structure and target pyramidal cells within a very narrow space. Such connectivity of double bouquet neurons has been proposed to represent a specialization of minicolumn inhibition within the primate order (del Rio and DeFelipe, 1997a; DeFelipe et al., 2002, 2006; Ballesteros-Yañez et al., 2005). Notably, the double bouquet axon bundles are associated with myelinated axons that comprise minicolumns in human cortex, although not all minicolumns were associated with CB-ir double bouquet cells (Ballesteros-Yañez et al., 2005).

While manifold differences have been reported between primates and nonprimates in terms of cortical GABAergic cell populations, our recent work revealed that there is actually a strong degree of conservation of inhibitory microcircuitry within several regions of the frontal cortex among human and nonhuman primates (Sherwood et al., 2009). Indeed, the density and distribution of interneurons expressing calcium-binding proteins across human and nonhuman primates closely adheres to general scaling rules without human-specific specializations in regions that are important for cognitive abilities such as language and mentalizing.

\section{NEUROPATHOLOGIES, INTERNEURONS, AND MINICOLUMNS}

Several neuropathological abnormalities in humans have been noted that involve minicolumns and interneurons. For example, decreased numbers of CB-ir interneurons have been reported consistently in the prefrontal cortex of patients with schizophrenia
(Beasley and Reynolds, 1997; Reynolds et al., 2001; Beasley et al., 2002; Cotter et al., 2002; Eyles et al., 2002; Chance et al., 2005; Sakai et al., 2008) while CR-ir interneuron density is preserved (Woo et al., 1998; Reynolds and Beasley, 2001; Zhang and Reynolds, 2002). The relationship between PV-ir neuron distributions and schizophrenia is less clear, with reports of a decrease in density (Beasley and Reynolds, 1997) or no change in density (Woo et al., 1997; Cotter et al., 2002). Alterations of minicolumn width (i.e., neuropil space) are also well-documented in schizophrenia (Reynolds et al., 2004; Casanova et al., 2005, 2008; Chance et al., 2005; Di Rosa et al., 2009). These changes in minicolumn morphology appear to be consistent with a developmental abnormality rather than a progressive pathological process (Casanova et al., 2005, 2008).

Alzheimer's disease is also associated with a selective decrease of cortical CB-ir neurons in humans (Ferrer et al., 1993; Nishiyama et al., 1993; Beasley et al., 2002) and has also been reported in the canine expression of dementia of the Alzheimer's type (Pugliese et al., 2004) while both PV- and CR-ir neuronal subpopulations are spared (Ferrer et al., 1993; Hof et al., 1993; Pugliese et al., 2004). However, it should be noted that not all forms of dementia are associated with a reduction in cortical calcium-binding proteincontaining interneurons (Hof et al., 1994; Gomez-Tortosa et al., 2001). The structure of minicolumns is selectively disrupted in Alzheimer's disease, and the loss of columnar organization was related to the number of neurofibrillary tangles (Buldyrev et al., 2000). Tangles cluster into columns and their numbers are positively correlated with degree of cognitive loss in Alzheimer's disease (Nagy et al., 1996). Minicolumn thinning was also noted in normal human aging and is a process that may be continuous with the increased risk of Alzheimer's disease over the age of 65 (Nagy et al., 1996).

It has been postulated that cortical minicolumn GABAergic inhibitory control is also compromised in autism (Casanova et al., 2003). However, while dysregulation of the calcium-binding protein-ir interneuron populations was recently demonstrated within the hippocampus of patients with autism (Lawrence et al., 2009), comparable data are not available for neocortical regions. Nonetheless, autism and Asperger's syndrome are associated with a narrowing of the minicolumns, specifically, the peripheral neuropil space (Casanova et al., 2002a,b,c, 2003). Because the peripheral neuropil space is dependent upon inhibitory interneuron populations, a deficit in GABAergic control is suspected. In particular, the modulation of minicolumnar activity would be altered for both local and long-range connectivity, resulting in collateral overexcitation among minicolumns (Casanova, 2008; Casanova and Trippe, 2009). Such a deficit is also suspected to contribute to the incidence of seizures in autistic individuals (Casanova et al., 2003). This relationship finds support in recent reports of deficits in both PV- and CR-ir interneurons with focal cortical dysplasias associated with epilepsy (Zamecnik et al., 2006; Barinka et al., 2009).

\section{CONCLUSIONS}

Interneuron subtypes are a major constituent of the peripheral neuropil space of minicolumns and the integrity of these local inhibitory circuits is critical for normal signal processing within the neocortex (Casanova et al., 2003). Highly conserved GABAergic neuron populations are targeted in certain 
neuropathologies, perhaps owing to dysregulated cell migration in autism and schizophrenia, or a cholinergic-regulated decline in Alzheimer's disease. In both Alzheimer's disease and normal senescence, cholinergic cell bodies are lost, making a significant contribution to declining cognitive functions (Whitehouse, 1992; Mesulam, 1996; Mega, 2000). Notably, disruption of cortical acetylcholine has also been implicated in schizophrenia and autism (for review see Sarter and Parikh, 2005; Lam et al., 2006), demonstrating the importance of this neurotransmitter system for normal cognitive processing. Acetylcholine is involved in calcium regulation (Rathouz et al., 1996; Griguoli et al., 2009) and in modulating the function of GABAergic interneurons. Many of the interneurons receiving cholinergic innervation appear to be double bouquet cells (Xiang et al., 1998). The loss of cholinergic input coincides with the loss of CB-ir interneurons, dysregulation of calcium homeostasis, and the breakdown of minicolumn structure (Chance et al., 2006).

Comparative data indicate that there are differences among human and nonhuman primate species in the cholinergic innervation of the frontal cortex (Raghanti et al., 2008). Interestingly, the morphology of $\mathrm{CB}$-containing interneurons has also been altered in primates, with a preponderance of double bouquet cells (Ballesteros-Yañez et al., 2005). Additionally, the major evolutionary alteration of minicolumn morphology is in minicolumn width. Humans deviate from other species in having a greater width of minicolumns in specific cortical areas, owing to constituents of the peripheral neuropil space, the most important predictor being the density of CB-ir double bouquet interneurons (Buxhoeveden et al., 2001b; Casanova et al., 2009).

\section{REFERENCES}

Ascoli, G. A., Alonso-Nanclares, L., Anderson, S. A., Barrionuevo, G., Benavides-Piccione, R., Burkhalter, A., Buzsáki, G., Cauli, B., DeFelipe, J., Fairén, A., Feldmeyer, D., Fishell, G., Fregnac, Y., Freund, T. F., Gardner, D., Gardner, E. P., Goldberg, J. H., Helmstaedter, M., Hestrin, S., Karube, F., Kisvárday, Z. F., Lambolez, B., Lewis, D. A., Marin, O., Markram, H., Muñoz, A., Packer, A., Petersen, C. C. H., Rockland, K. S., Rossier, J., Rudy, B., Somogyi, P., Staiger, J. F., Tamas, G., Thomson, A. M., Toledo-Rodriguez, M., Wang, Y., West, D. C., and Yuste, R. (2008). Petilla terminology: nomenclature of features of GABAergic interneurons of the cerebral cortex. Nat. Rev. Neurosci. 9, 557-568.

Ballesteros-Yañez,I., Munoz,A., Contreras, J., Gonzalez, J., Rodriguez-Veiga, E., and DeFelipe, J. (2005). Double bouquet cell in the human cerebral cortex and a comparison with other mammals. J. Comp. Neurol. 486, 344-360.

Barinka, F., Druga, R., Marusic, P., Krsek, P., and Zamecnik, J. (2009). Calretinin immunoreactivity in focal cortical dysplasisias and in non-malformed epileptic cortex. Epilepsy Res. doi:10.1016/j.eplepsyres.2009.09.021.

Taken together, the unique prevalence of CB-ir double bouquet cells in the primate cortex, human-specific alterations in minicolumn width, disruption of cholinergic innervation and the loss of CB-ir interneurons in neuropathological processes in addition to their importance to the integrity of minicolumn structure point to a specialized function for these interneurons within the primate cortex.

Thus, variability not only in the connectivity of the minicolumn but also in the subtle subcomponents of the columnar organization such as composition of interneuron subtypes are a primary source of interspecific differences. Accordingly, both intra- and interspecific variation in cortical minicolumn morphology points in favor of diversity and an interpretation of the cortical minicolumn phenotype more strongly rooted in an evolutionary view. This perspective embraces complexity and the myriad morphological differences that biological species have evolved. More than 50 years after Mountcastle's observation of the cortical minicolumn and the 150 years since Darwin's (1859) highly influential evolutionary synthesis, it is perhaps fitting that we fuse the concept of the cortical minicolumn into an evolutionary perspective that acknowledges the eclectic nature of biology and the all-important contribution of variation to evolution.

\section{ACKNOWLEDGMENTS}

We thank Cheryl D. Stimpson for technical assistance. This work was supported by the National Science Foundation (BCS-0515484, BCS-0549117, BCS-0827531, BCS-0550209, BCS-0827546, DGE0801634), the National Institutes of Health (NS42867), the WennerGren Foundation for Anthropological Research, and the James S. McDonnell Foundation (22002078).

patterns in the language area of human, chimpanzee, and rhesus monkey brains. Laterality 5, 315-330.

Buxhoeveden, D. P., and Casanova, M. F. (2002a). The minicolumn and evolution of the brain. Brain Behav. Evol. 60, 125-151.

Buxhoeveden, D. P., and Casanova, M. F. (2002b). The minicolumn hypothesis in neuroscience. Brain 125, 935-951.

Buxhoeveden, D. P., Switala, A. E., Litaker, M., Roy, E., and Casanova, M. F. (2001a). Lateralization of minicolumns in human planum temporale is absent in nonhuman primate cortex. Brain Behav. Evol. 57, 349-358.

Buxhoeveden, D. P., Switala, A. E., Roy, E., Litaker, M., and Casanova, M. F. (2001b). Morphological differences between minicolumns in human and nonhuman primate cortex. Am. J. Phys. Anthropol. 115, 361-371.

Buzsaki, G., Geisler, C., Henze, D. A. and Wang, X. J. (2004). Interneuron Diversity series: circuit complexity and axon wiring economy of cortical interneurons. Trends Neurosci. 27, 186-193.

Casanova,M.F.(2006). Neuropathological and gentic findings in autism: The significance of a putative minicolumnopathy. Neuroscientist 12, 435-441.
Casanova, M.F. (2008). The significance of minicolumnar size variability in autism: a perpective from comparative anatomy. In Autism Current Theories and Evidence, Current Clinical Neurology, A. Zimmerman, ed. (The Humana Press, Inc. Totowa), pp. 349-360.

Casanova, M. F., Buxhoeveden, D., and Brown, C. (2002a). Clinical and macroscopic correlates of minicolumnar pathology in autism. J. Child Neurol. 17, 692-695.

Casanova, M. F., Buxhoeveden, D., Switala, A. E., and Roy, E. (2002b). Asperger's syndrome and cortical neuropatholgy. J. Child Neurol. 17, 142-145.

Casanova, M. F., Buxhoeveden, D., Switala, A. E., and Roy, E. (2002c). Minicolumnar pathology in autism. Neurology 58, 428-432.

Casanova, M. F., Buxhoeveden, D., and Gomez, J. (2003). Disruption in the inhibitory architecture of the cell minicolumn: implications for autism. Neuroscientist 9, 496-507.

Casanova, M. F., de Zeeuw, L., Switala, A., Kreczmanski, P., Korr, H., Ulfig, N., Heinsen, H., Steinbusch, H. W. M., and Schmitz, C. (2005). Mean cell spacing abnormalities in the neocortex of patients with schizophrenia. Psychiatry Res 133, 1-12. 
Casanova, M. F., Kreczmanski, P., Trippe, J., Switala, A., Heinsen, H., Steinbusch, H. W. M., and Schmitz, C. (2008). Neuronal distribution in the neocortex of schizophrenic patients. Psychiatry Res 158, 267-277.

Casanova, M. F., Switala, A., Trippe, J., and Fitzgerald, M. (2007). Comparative minicolumnar morphometry of three distinguished scientists. Autism $11,557-569$.

Casanova, M. F., and Tilquist, C. R. (2008). Encephalisation, emergent properties, and psychiatry: a minicolumnar perspective. Neuroscientist $14,101-118$.

Casanova, M. F., and Trippe, J. (2009). Radial cytoarchitecture and patterns of cortical connectivity in autism. Phil. Trans. R. Soc. B. 364, 1433-1436.

Casanova, M. F., Trippe, J., Tillquist,C., and Switala, A. E. (2009). Morphometric variability of minicolumns in the striate cortex of Homo sapiens, Macaca mulatta, and Pan troglodytes. J. Anat. 214, 226-234.

Chance, S. A., Casanova, M. F., Switala, A., Crow, T. J., and Esiri, M. M. (2006). Minicolumn thinning in temporal lobe association cortex but not primary auditory cortex in normal human ageing. Acta Neuropathol. 111, 459-464.

Chance, S. A., Walker, M., and Crow, T. J. (2005). Reduced density of calbindinimmunoreactive interneurons in the planum temporale in schizophrenia. Brain Res. 1046, 32-37.

Condé, F., Lund, J. S., Jacobowitz, D. M., Baimbridge, K. G., and Lewis, D. A. (1994). Local circuit neurons immunoreactive for calretinin, calbindin D-28k or parvalbumin in monkey prefrontal cortex: distribution and morphology. J. Comp. Neurol. 341, 95-116.

Constantinidis, C., Williams, G. V., and Goldman-Rakic, P. S. (2002). A role for inhibition in shaping the temporal flow of information in prefrontal cortex. Nat. Neurosci. 5, 175-180.

Cotter, D., Landau, S., Beasley, C., Stevenson, R., Chana, G., MacMillan, L., and Everall, I. (2002). The density and spatial distribution of GABAergic neurons, labelled using calcium binding proteins, in the anterior cingulate cortex in major depressive disorder, bipolar disorder, and schizophrenia. Biol. Psychiatry 51, 377-386.

Darwin, C. (1859). The Origin of Species: 150th Anniversary Edition. Signet Classic (Rep Anv Edition, 2003) New York.

DeFelipe, J. (1997). Types of neurons, synaptic connections and chemical characteristics of cells immunoreactive for calbindin-D28k, parvalbumin and calretinin in the neocortex. J. Chem. Neuroanat. 14, 1-19.
DeFelipe, J. (2002). Cortical interneurons: from Cajal to 2001. Prog. Brain Res. 136, 215-238.

DeFelipe, J., Alonso-Nanclares, L., and Arellano, J. I. (2002). Microstructure of the neocortex: comparative aspects. J. Neurocytol. 31, 299-316.

DeFelipe, J., Ballesteros-Yañez, I., Inda, M. C., and Munoz,A. (2006). Doublebouquet cells in the monkey and human cerebral cortex with special reference to areas 17 and 18. Prog. Brain Res. 154, 15-32.

DeFelipe, J., Gonzalez-Albo, M. C., Del Rio, M. R., and Elston, G. N. (1999). Distribution and patterns of connectivity of interneurons containing calbindin, calretinin, and parvalbumin in visual areas of the occipital and temporal lobes of the macaque monkey. J. Comp. Neurol. 412, 515-526.

DeFelipe, J., Hendry, S. H., Hashikawa, T., Molinari, M., and Jones, E. G. (1990). A microcolumnar structure of monkey cerebral cortex revealed by immunocytochemical studies of double bouquet cell axons. Neuroscience 37, 655-673.

DeFelipe, J., Hendry, S. H., and Jones, E. G. (1989). Synapses of double bouquet cells in monkey cerebral cortex visualized by calbindin immunoreactivity. Brain Res. 503, 49-54.

del Rio, M. R., and DeFelipe, J. (1997a). Double bouquet cell axons in the human temporal neocortex: relationship to bundles of myelinated axons and colocalization of calretinin and calbindin D-28k immunoreactivities. J. Chem. Neuroanat. 13, 243-251.

del Rio, M. R., and DeFelipe, J. (1997b). Synaptic connections of calretininimmunoreactive neurons in the human neocortex. J. Neurosci. 17, 5143-5154.

Di Rosa, E., Crow, T. J., Walker, M. A., Black, G., and Chance, S. A. (2009). Reduced neuron density, enlarged minicolumn spacing and altered ageing effects in fusiform cortex in schizophrenia. Psychiatry Res 166, 102-115.

Escobar, M. I., Pimenta, H., Caviness Jr, V. S., Jacobson, M., Crandall, J. E., and Kosik, K. S. (1986). Architecture of apical dendrites in the murine neocortex: dual apical dendritic systems. Neuroscience 17, 975-989.

Eyles, D. W., McGrath, J. J., and Reynolds, G. P. (2002). Neuronal calcium-binding proteins and schizophrenia. Schizophr. Res. 57, 27-34.

Favorov, O.V., and Diamond, M.E. (1990). Demonstration of discrete placedefined columns-segregates-in the cat SI. J. Comp. Neurol. 298, 97-112.

Feldman, M. L., and Peters, A. (1974). A study of barrels and pyramidal dendritic clusters in the cerebral cortex. Brain Res. 77, 55-76.

Ferrer, I., Tuñon, T., Serrano, M. T., Casas, R., Alcantara, S., Zujar, M. J., and Rivera, R. M. (1993). Calbindin D-28k and parvalbumin immunoreactivity in the frontal cortex in patients with frontal lobe dementia of non-Alzheimer type associated with amyotrophic lateral sclerosis. J. Neurol. Neurosurg. Psychiatry 56, 257-261.

Fleischauer, K., Petsche, H., and Wittkowski, W. (1972). Vertical bundles of dendrites in the neocortex. $Z$. Anat. Entwickl. Gesch. 136, 213-223.

Gabbott, P. L., and Bacon, S. J. (1996). Local circuit neurons in the medial prefrontal cortex (areas 24a,b,c, 25 and 32) in the monkey: II. Quantitative areal and laminar distributions. J. Comp. Neurol. 364, 609-636.

Gabbott, P. L., Dickie, B. G., Vaid, R. R., Headlam, A. J., and Bacon, S. J. (1997). Local-circuit neurones in the medial prefrontal cortex (areas 25, 32 and 24b) in the rat: morphology and quantitative distribution. J. Comp. Neurol. 377, 465-499.

Glezer, I. I., Hof, P. R., Leranth, C., and Morgane, P. J. (1993). Calcium-binding protein-containing neuronal populations in mammalian visual cortex: a comparative study in whales, insectivores, bats, rodents, and primates. Cereb. Cortex 3, 249-272.

Glezer, I. I., Hof, P. R., and Morgane, P. J. (1992). Calretinin-immunoreactive neurons in the primary visual cortex of dolphin and human brains. Brain Res. 595, 181-188.

Glezer, I. I., Hof, P. R., and Morgane, P. J. (1998). Comparative analysis of calcium-binding protein-immunoreactive neuronal populations in the auditory and visual systems of the bottlenose dolphin (Tursiops truncatus) and the macaque monkey (Macaca fascicularis). J. Chem. Neuroanat. 15, 203-237.

Glezer, I. I., and Morgane, P. J. (1990). Ultrastructure of synapses and golgi analysis of neurons in neocortex of the lateral gyrus (visual cortex) of the dolphin and pilot whale [published erratum appears in Brain Res. Bull. (1990) 24, 639-40]. Brain Res. Bull. $24,401-427$.

Gomez-Tortosa, E., Sanders, J. L., Newell, K., and Hyman, B. T. (2001). Cortical neurons expressing calcium binding proteins are spared in dementia with Lewy bodies. Acta Neuropathol. (Berl.) $101,36-42$.

Griguoli, M., Scuri, R., Ragozzino, D., and Cherubini, E. (2009). Activation of nicotinic acetylcholine receptors enhances a slow calcium-dependent potassium conductance and reduces the firing of stratum oriens interneurons. Eur. J. Neurosci. 30, 1011-1022.

Hendry, S. H. C. (1987). Recent advances in understanding the intrinsic circuitry of the cerebral cortex. In Higher Brain Functions: Recent Explorations of the Brain's Emergent Properties, S. P. Wise, ed. (New York, Wiley), pp. 241-283.

Hendry, S. H. C., Jones, E. G., Emson, P. C., Lowson, D. E. M., Heizmann, C W., and Streit, P. (1989). Two classes of cortical GABA neurons defined by differential calcium binding protein immunoreactivities. Exp. Brain Res. 76, 467-472.

Hendry, S. H. C., Schwark, H. D., Jones, E. G., and Yan, J. (1987). Number and proportions of GABA-immunoreactive neurons in different areas of monkey cerebral cortex. J. Neurosci. 7, 1503-1519.

Herculano-Houzel, S., Collins, C. E., Wong, P., Kaas, J. H., and Lent, R. (2008). The basic nonuniformity of the cerebral cortex. Proc. Natl. Acad. Sci. U.S.A. 105, 12593-12598.

Hof, P. R., Bogaert, Y. E., Rosenthal, R. E., and Fiskum, G. (1996). Distribution of neuronal populations containing neurofilament protein and calcium-binding proteins in the canine neocortex: regional analysis and cell typology. $J$. Chem. Neuroanat. 11, 81-98.

Hof, P. R., Glezer, I. I., Condé, F., Flagg, R. A., Rubin, M.B., Nimchinsky,E.A., and Vogt Weisenhorn,D.M.(1999).Cellular distribution of the calcium-binding proteins parvalbumin, calbindin, and calretinin in the neocortex of mammals: phylogenetic and developmental patterns. J. Chem. Neuroanat. 16, 77-116.

Hof, P. R., Glezer, I. I., Nimchinsky, E. A., andErwin,J.M. (2000). Neurochemical and cellular specializations in the mammalian neocortex reflect phylogenetic relationships: evidence from primates, cetaceans, and artiodactyls. Brain Behav. Evol. 55, 300-310.

Hof, P. R., Nimchinsky, E. A., BuéeScherrer, V., Buée, L., Nasrallah, J., Hottinger, A. F., Purohit, D. P., Loerzel, A. J., Steele, J. C., Delacourte, A., Bouras, C., Morrison, J. H., and Perl, D. P. (1994). Amyotrophic lateral sclerosis/parkinsonism-dementia complex of Guam: quantitative neuropathology, immunohistochemical analysis of neuronal vulnerability, and comparison with related neurodegenerative disorders. Acta Neuropathol. 88, 397-404.

Hof, P. R., Nimchinsky, E. A., Celio, M. R., Bouras, C., and Morrison, J. H. (1993). Calretinin-immunoreactive neocortical interneurons are unaffected in Alzheimer's disease. Neurosci. Lett. 152, 145-148. 
Hof, P. R., and Sherwood, C. C. (2005). Morphomolecular neuronal phenotypes in the neocortex reflect phylogenetic relationships among certain mammalian orders. Anat. Rec. 287A, 1153-1163.

Hof, P. R., and Van der Gucht, E. (2007). Structure of the cerebral cortex of the humpback whale, Megaptera novaeangliae (Cetacea, Mysticeti, Balaenopteridae). Anat. Rec. 290, 1-31.

Kaas, J. H., Nelson, R. J., Sur, M. and Merzenich,M.M.(1981). Organisation of somatosensory cortex in primates. In The Organization of the Cerebral Cortex, F. O. Schmitt, F. G. Worden, G. Adelman, and S. G. Dennis, eds (Cambridge MA, MIT Press), pp. 237-261.

Kawaguchi, Y., and Kubota, Y. (1997). GABAergic cell subtypes and their synaptic connections in rat frontal cortex. Cereb. Cortex 7, 476-486.

Kohn, A., Pinheiro, A., Tommerdahl, M. A., and Whitsel, B. L. (1997). Optical imaging in vitro provides evidence for the minicolumnar nature of cortical response. Neuroreport 8, 3513-3518.

Kubota, Y., Hattori, R., and Yui, Y. (1994). Three distinct subpopulations of GABAergic neurons in rat frontal agranular cortex. Brain Res. 649, 159-173.

Lam, K. S., Aman, M. G., and Arnold, L. E. (2006). Neurochemical correlates of autistic disorder: a review of the literature. Res. Dev. Disabil. 27, 254-289.

Lawrence, Y.A., Kemper, T. L., Bauman, M. L., and Blatt, G. J. (2009). Parvalbumin-, calbindin-, and calretinin-immunoreactivehippocampal interneuron density in autism. Acta Neurol. Scand. doi:10.1111/ j.1600-0404.2009.01234.x

Li, C. X., Callaway, J. C., and Waters, R. S. (2002). Removal of GABAergic inhibition alters subthreshold input in neurons in forepaw barrel subfield (FBS) in rat first somatosensory cortex (SI) after digit stimulation. Exp. Brain Res. 145, 411-428.

Lund, J. S., and Lewis, D. A. (1993). Local circuit neurons of developing and mature macaque prefrontal cortex: Golgi and immunocytochemical characteristics. J. Comp. Neurol. 328, 282-312.

Manger, P. R. (2006). An examination of cetacean brain structure with a novel hypothesis correlating thermogenesis to the evolution of a big brain. Biol. Rev. 81, 293-338.

Marino, L. (2002). Convergence of complex cognitive abilities in cetaceans and primates. Brain Behav. Evol. 59, 21-32.

Marino, L., Butti, C., Connor, R. C., Fordyce, R. E., Herman, L. M., Hof, P. R., Lefebvre, L., Lusseau, D.,
McCowan, B., Nimchinsky, E. A., Pack, A. A., Reidenberg, J. S., Reiss, D., Rendell, L., Uhen, M. D., Van der Gucht, E., and Whitehead, H. (2008). A claim in search of evidence: reply to Manger's thermogenesis hypothesis of cetacean brain structure. Biol. Rev. 83, 417-440.

Marino. L., Connor, R. C., Fordyce, R. E., Herman, L. M., Hof, P. R., Lefebvre, L., Lusseau, D., McCowan, B., Nimchinsky, E.A., Pack, A. A., Rendell, L., Reidenberg, J. S., Reiss, D., Uhen, M. D., Van der Gucht, E., and Whitehead, H. (2007). Cetaceans have complex brains for complex cognition. PLoS Biol. 5, e139. doi:10.1371/journal. pbio.0050139.

Mega,M.S. (2000). The cholinergic deficit in Alzheimer's disease: impact on cognition, behavior and function. Int. J. Neuropsychopharmacol. 3, S3-S12.

Mesulam, M.M.(1996). The systems-level organization of cholinergic innervation in the human cerebral cortex and its alterations in Alzheimer's disease. Prog. Brain Res. 109, 285-297.

Morgane, P. J., Glezer, I. I., and Jacobs, M. S. (1988). Visual cortex of the dolphin: an image analysis study. J. Comp. Neurol. 273, 3-25.

Mountcastle, V. B. (1997). The columnar organization of the neocortex. Brain 120, 701-722.

Mountcastle, V. B., Berman, A. L., and Davies, P. (1955). Topographic organization and modality representation in the first somatic area of cat's cerebral cortex by method of single unit analysis. Am. J. Physiol. 183, 464.

Nagy, Z., Esiri, M. M., Jobst, K. A., Morris, J. H., King, E. M., McDonald, B., Litchfield, S., and Barneston, L. (1996). Clustering of pathological features in Alzheimer's disease: clinical and neuroanatomical aspects. Dementia 7 , 121-127.

Nishiyama, E., Ohwada, J., Iwamoto, N., and Arai, H. (1993). Selective loss of calbindin D28K-immunoreactive neurons in the cortical layer II in brains of Alzheimer's disease: a morphometric study. Neurosci. Lett. 163, 223-226.

Petanjek, Z., Kostovic, I., and Esclapez, M. (2009). Primate-specific origins and migration of cortical GABAergic neurons. Front. Neuroanat. 3:26. doi:10.3389/neuro.05.026.2009

Peters, A., and Kara, D. (1987). The neuronal composition of area 17 in rat visual cortex. The organization of pyramidal cells. IV. J. Comp. Neurol. 260, 573-559.

Peters, A., and Sethares, C. (1991). Organization of pyramidal neurons in area 17 of monkey visual cortex. J. Comp. Neurol. 306, 1-23.
Peters, A., and Sethares, C. (1996) Myelinated axons and the pyramidal cell modules in monkey primary visual cortex. J. Comp. Neurol. 365, 232-255.

Peters, A., and Sethares, C. (1997). The organization of double bouquet cells in monkey striate cortex. J. Neurocytol. 26,779-797.

Peters, A., and Walsh, T.M. (1972). A study of the organization of apical dendrites in the somatic sensory cortex of the rat. J. Comp. Neurol. 144, 253-268.

Peters, A., and Yilmaz, E. (1993).Neuronal organization in area 17 of cat visual cortex. Cereb. Cortex 3, 49-68.

Povysheva, N. V., Zaitsev, A. V., Rotaru, D. C., Gonzalez-Burgos, G., Lewis, D. A. and Krimer, L.S. (2008). Parvalbuminpositive basket interneurons in monkey and rat prefrontal cortex. $J$. Neurophysiol. 100, 2348-2360.

Preuss, T. M., and Coleman, G. Q. (2002). Human-specific organization of primary visual cortex: alternating compartments of dense Cat-301 and calbindin immunoreactivity in layer 4A. Cereb. Cortex 12, 671-691.

Preuss, T. M., and Goldman-Rakic, P. S. (1991). Architectonics of the parietal and temporal association cortex in the strepsirhine primate Galago compared to the anthropoid primate Macaca. J. Comp. Neurol. 310, 475-506.

Pugliese, M., Carrasco, J. L., Geloso, M. C., Mascort, J., Michetti, F., and Mahy, N. (2004). $\gamma$-aminobutyric acidergic interneuron vulnerability to aging in canine prefrontal cortex. J. Neurosci. Res. 77, 913-920.

Raghanti, M. A., Stimpson, C. D., Marcinkiewicz, J. L., Erwin, J. M., Hof, P. R., and Sherwood, C. C. (2008). Cholinergic innervation of the frontal cortex: Differences among humans, chimpanzees, and macaque monkeys. J. Comp. Neurol. 506, 409-424.

Rakic, P. (2008). Confusing cortical columns. Proc. Natl. Acad. Sci. U.S.A. 105, 12099-12100.

Rakic, P. and Kornack, D. R. (2001) Neocortical expansion and elaboration during primate evolution: a view from neuroembryology In Evolutionary Anatomy of the Primate Cerebral cortex, D. Falk and K. R. Gibson, eds (Cambridge, Cambridge University Press), pp. 30-56.

Rao, S. G., Williams, G. V., and GoldmanRakic, P. S. (1999). Isodirectional tuning of adjacent interneurons and pyramidal cells during working memory: evidence for microcolumnar organization in PFC. J. Neurophysiol. 81, 1903-1916.

Rathouz, M. M., Vijayaraghanvan, S., and Berg, D. K. (1996). Elevation of intracellular calcium levels in neurons by nicotinic acetylcholine receptors. Mol. Neurobiol. 12, 117-131.

Reynolds, G., Abdul-Monim, Z., Neill, J., and Zhang, Z. (2004). Calcium binding protein markers of GABA deficits in schizophrenia- postmortem studies and animal models. Neurotox. Res. 6 , 57-61.

Reynolds, G. P., and Beasley, C. L. (2001). GABAergic neuronal subtypes in the human frontal cortex--development and deficits in schizophrenia. J. Chem. Neuroanat. 22, 95-100.

Reynolds, G. P., Zhang, Z. J., and Beasley, C.L. (2001). Neurochemical correlates of cortical GABAergic deficits in schizophrenia: selective losses of calcium binding protein immunoreactivity. Brain Res. Bull. 55, 579-584.

Rilling, J. K., Glasser, M. F., Preuss, T. M., Ma,X., Zhao, T., Hu, X., and Behrenns, T. E. J. (2008). The evolution of the arcuate fasciculus revealed with comparative DTI. Nat. Neurosci. 11, 426-428.

Rockel, A. J., Hiorns, R. W., and Powell, T. P. (1980). The basic uniformity in the structure of the neocortex. Brain 103, 221-244

Sakai, T., Oshima, A., Nozaki, Y., Ida, I., Haga, C., Akiyama, H., Nazazato, Y., and Mikuni, M. (2008). Changes in density of calcium-binding-proteinimmunoreactive GABAergic neurons in prefrontal cortex in schizophrenia and bipolar disorder. Neuropathology 28, 143-150.

Sarter, M., and Parikh, V. (2005). Choline transporters, cholinergic transmission and cognition. Nat. Rev. Neurosci. 6, 48-56.

Schenker, N. M., Buxhoeveden, D., Blackmon, W. L., Amunts, K., Zilles, K., and Semendeferi, K. (2008).A comparative quantitative analysis of cytoarchitecture and minicolumnar organization in Broca's area in humans and great apes. J. Comp. Neurol. 510, 117-128.

Schlaug, G., Schleicher, A., and Zilles, K. (1995). Quantitative analysis of the columnar arrangement of neurons in the human cingulate cortex. J. Comp. Neurol. 351, 441-452.

Seldon, H. L. (1981). Structure of human auditory cortex I: cytoarchitectonics and dendritic distributions. Brain Res. 229, 277-294.

Sherwood, C. C., Raghanti, M. A., Stimpson, C. D., Bonar, C. J., de Sousa, A. J., Preuss, T.M., and Hof,P.R. (2007). Scaling of inhibitory interneurons in areas $\mathrm{V} 1$ and $\mathrm{V} 2$ of anthropoid primates as revealed by calcium-binding protein immunohistochemistry. Brain Behav. Evol. 69, 176-195.

Sherwood, C. C., Raghanti, M. A., Stimpson, C. D., Spocter, M. A., 
Uddin, M., Boddy, A. M., Wildman, D. E., Bonar, C. J., Lewandowski, A. L., Phillips, K. A., Erwin, J. M. and Hof, P. R. (2009). Inhibitory interneurons of the human prefrontal cortex display conserved evolution of the phenotype and related genes. Proc. Royal Soc. B. Bio. Sci. doi: 10.10981/rspb.2009.1831

Sherwood, C. C., Stimpson, C. D., Butti, C., Bonar, C. J., Newton, A. L., Allman, J. M., and Hof, P. R. (2009). Neocortical neuron types in Xenarthra and Afrotheria: implications for brain evolution in mammals. Brain Struct. Funct. 213, 301-328.

Skoglund, T. S., Pascher, R., and Berthold, C. H. (1996). Heterogeneity in the columnar number of neurons in different neocortical areas in the rat. Neurosci. Lett. 208, 97-100.

Sohal, V. S., Zhang, F., Yizhar, O., and Deisseroth, K. (2009). Parvalbumin neurons and gamma rhythms enhance cortical circuit performance. Nature 459, 698-702.

Somogyi, P., Tamas, G., Lujan, R., and Buhl, E. H. (1998). Salient features of synaptic organisation in the cerebral cortex. Brain Res. Rev. 26, 113-135.
Tommerdahl, M., Favorov, O. V., Whitsel, B. L., Nakhle, B., and Gonchar, Y. A. (1993). Minicolumnar activation patterns in cat and monkey S1 cortex. Cereb. Cortex 3, 399-411.

Von Bonin, G., and Mehler,W.R.(1971). On columnar arrangement of nerve cells in cerebral cortex. Brain Res. 27, 1-9.

Wang, Y., Caspary, D., and Salvi, R. J. (2000a). GABA-A antagonist causes dramatic expansion of tuning in primary auditory cortex. Neuroreport 11 , 1137-1140.

Wang, Y., Fujita, I., and Murayama, Y. (2000b). Neuronal mechanisms of selectivity for object features revealed by blocking inhibition in inferotemporal cortex. Nat. Neurosci. 3, 807-813.

White, E. L., and Peters, A. (1993). Cortical modules in the posteromedial barrel subfield (Sml) of the mouse. J. Comp. Neurol. 334, 86-96.

Whitehouse, P. J. (1992). Alzheimer's disease: relationship of cognition and behavior to neurochemistry. Int Psychogeriatr. 4, 71-78.

Woo, T. U., Miller, J. L., and Lewis, D. A. (1997). Schizophrenia and the parvalbumin-containing class of cortical local circuit neurons. Am. J. Psychiatry 154, 1013-1015.

Woo, T. U., Whitehead, R. E., Melchitzky, D. S., and Lewis, D. A. (1998). A subclass of prefrontal Gamma-aminobutyric acid axon terminals are selectively altered in schizophrenia. Proc. Natl. Acad. Sci. U.S.A. 95, 5341-5346.

Xiang, Z., Huguenard, J. R., and Prince, D. A. (1998). Cholinergic switching within neocortical inhibitory networks. Science 281, 985-988.

Zaitsev, A. V., Gonzalez-Burgos, G., Povysheva, N. V., Kroner, S., Lewis, D. A., and Krimer, L. S. (2005) Localization of calcium-binding proteins in physiologically and morphologically characterized interneurons of monkey dorsolateral prefrontal cortex. Cereb. Cortex 15, 1178-1186.

Zamecnik, J., Krsek, P., Druga, R., Marusic, P., Benes, V., Tichy, M., and Komarek, V. (2006). Densities of parvalbumin-immunoreactive neurons in non-malformed hippocampal sclerosis-temporal neocortex and in cortical dysplasias. Brain Res. Bull. 68, 474-481.

Zhang, Z. J., and Reynolds, G. P. (2002). A selective decrease in the relative density of parvalbuminimmunoreactive neurons in the hippocampus in schizophrenia. Schizophr. Res. 55, 1-10.

Conflict of Interest Statement: The authors declare that the research was conducted in the absence of any commercial or financial relationships that could be construed as a potential conflict of interest.

Received: 01 December 2009; paper pending published: 15 December 2009; accepted: 07 January 2010; published online: 05 February 2010.

Citation: Raghanti MA, Spocter MA, Butti C, Hof PR and Sherwood CC (2010) A comparative perspective on minicolumns and inhibitory GABAergic interneurons in the neocortex. Front. Neuroanat. 4:3. doi: 10.3389/neuro.05.003.2010

Copyright $\odot 2010$ Raghanti, Spocter, Butti, Hof and Sherwood. This is an open-access article subject to an exclusive license agreement between the authors and the Frontiers Research Foundation, which permits unrestricted use, distribution, and reproduction in any medium, provided the original authors and source are credited. 